\title{
Epidemic Influenza Seasons from 2008 to 2018 in Poland: A Focused Review of Virological Characteristics
}

\author{
Sainjargal Byambasuren, Iwona Paradowska-Stankiewicz, \\ and Lidia B. Brydak
}

\begin{abstract}
The objective of this review was to elaborate on changes in the virological characteristics of influenza seasons in Poland in the past decade. The elaboration was based on the international influenza surveillance system consisting of Sentinel and non-Sentinel programs, recently adopted by Poland, in which professionals engaged in health care had reported tens of thousands of cases of acute upper airway infections. The reporting was followed by the provision of biological specimens collected from patients with suspected influenza and influenza-like infection, in which the causative contagion was then verified with molecular methods. The peak incidence of influenza infections has regularly been in JanuaryMarch each epidemic season. The number of tested specimens ranged from 2066 to 8367 per season from 2008/2009 to 2017/2018.
\end{abstract}

S. Byambasuren

EASTMED Family Medicine, Acupuncture, Aesthetic

Medicine, Warsaw, Poland

I. Paradowska-Stankiewicz $(\bowtie)$

Department of Epidemiology of Infectious Diseases and Surveillance, National Institute of Public Health -

National Institute of Hygiene, Warsaw, Poland

e-mail: istankiewicz@pzh.gov.pl

L. B. Brydak

Department of Influenza Research, National Influenza

Center at the National Institute of Public Health - National Institute of Hygiene in Warsaw, Warsaw, Poland
Type A virus predominated in nine out of the ten seasons and type B virus of the Yamagata lineage in the 2017/2018 season. Concerning the influenza-like infection, respiratory syncytial virus predominated in all the seasons. There was a sharp increase in the proportion of laboratory confirmations of influenza infection from season to season in relation to the number of specimens examined, from $3.2 \%$ to $42.4 \%$ over the decade. The number of confirmations, enabling a prompt commencement of antiviral treatment, related to the number of specimens collected from patients and on the virological situation in a given season. Yet influenza remains a health scourge, with a dismally low yearly vaccination rate, which recently reaches just about $3.5 \%$ of the general population in Poland.

\section{Keywords}

Diagnostics · Epidemic seasons · Influenza · Sentinel program $\cdot$ Surveillance $\cdot$ Virological characteristics

\section{Introduction}

Influenza is a contemporary worldwide scourge. There were three influenza pandemics in the nineteenth century. The most tragic one, the Spanish flu, caused 50-100 m deaths and considerable 
economic losses, according to the contemporary estimates. The WHO proposed a global program for the surveillance of influenza in 1947, based on the epidemiological and virological research (Bednarska et al. 2016a; Broberg et al. 2015). This program has currently assumed a form of the Global Influenza Surveillance and Response System, Poland has been participating in since 1957. The surveillance system has included the Sentinel program as of 2004. The surveillance is pursued in cooperation with general practitioners and laboratories of 16 Provincial SanitaryEpidemiological Stations across the country. The epidemiological part of this surveillance is based on reports of cases and suspected cases of influenza and influenza-like illnesses. The virological monitoring is based on a laboratory confirmation of infection using molecular biology methods (Bednarska et al. 2016b). In addition, virological data recorded in the non-Sentinel program are collected from hospitals and private physicians.

Influenza infection, with the occurrence of complications, mortality, and absenteeism at work, bears outstanding health and socioeconomic burdens. This study was designed to present and compare the virological characteristics of influenza seasons in Poland in the last decade, based on the epidemiological data from the national influenza surveillance system.

\section{$2 \quad$ Material and Results}

This article was based on the influenza surveillance system consisting of Sentinel and non-Sentinel programs, recently adopted by Poland, in which health-care professionals are obliged to report cases of acute upper airway infections. Preliminary diagnosis was done in 16 Provincial Sanitary-Epidemiological Stations throughout the country, followed by the sampling of nasopharyngeal specimens in case of suspected influenza and influenza-like infections. The reports were collated and coordinated by the Department of Influenza Research of the National Influenza Center at the National Institute of Public Health-National Institute of Hygiene (NIPH-
$\mathrm{NIH}$ ) in Warsaw, where the causative contagion was then verified using molecular methods. Data were collected at weekly cycles for 52 weeks beginning as of October and ending in September of a successive year. Yearly number of collected and tested specimens in the surveillance system ranged from 2066 to 8367 during the 10-year period reviewed in this study (Cieślak et al. 2017, 2018).

The study material consisted of nasopharyngeal swabs or bronchial tree lavage collected from patients presenting symptoms of upper airway infection across all age groups. Specimens were collected through the epidemic seasons from $2008 / 2009$ to $2017 / 2018$. They were further investigated using real-time polymerase chain reaction (PCR) or conventional multiplex PCR to isolate genetic material of invading contagions and thus to identify the influenza or influenza-like type of virus.

In total, during the ten epidemic seasons, physicians collected and transferred to the NIPH-NIH center 44,566 samples, which gives an average of 4456 samples per season (Table 1). In the 2008/2009-2017/2018 epidemic seasons, influenza type A and B viruses and influenza-like illnesses of different severity were recorded. The percentage of confirmed influenza virus infections ranged from $21.4 \%$ in 2011/2012 to $96.7 \%$ in 2017/2018. There was an apparent inverse relation between the frequency of influenza and influenza-like infections; the more of the former, the fewer of the latter. In nine out of the ten seasons, type A virus predominated, with subtype $\mathrm{A} / \mathrm{H} 1 \mathrm{~N} 1 / \mathrm{pdm} 09$ in seven and $\mathrm{A} / \mathrm{H} 3 \mathrm{~N} 2 /$ in two seasons. The influenza type $\mathrm{B}$ virus of the Yamagata lineage predominated in the 2017/2018 season (Table 1).

Infections caused by influenza-like viruses were also recorded. The following viruses were identified: human respiratory syncytial virus (RSV) type A and type B, parainfluenza virus types 1-4, human metapneumovirus (hMV), human adenovirus (ADV), human rhinovirus (RV), human coronavirus 229/NL63 and OC43/ HKU1, and enterovirus. The percentage of confirmed influenza-like infections among all influenza infections ranged from $78.6 \%$ in $2011 / 2012$ 
Table 1 Virological characteristics of influenza and influenza-like infections during a decade of the 2008/2009-2017/ 2018 epidemic seasons in Poland

\begin{tabular}{|c|c|c|c|c|}
\hline $\begin{array}{l}\text { Epidemic } \\
\text { season }\end{array}$ & $\begin{array}{l}\text { No. of samples with } \\
\text { confirmed infection }\end{array}$ & $\begin{array}{l}\text { Percentage of influenza/ } \\
\text { influenza-like viral infections } \\
(\%)\end{array}$ & $\begin{array}{l}\text { Predominant subtype of } \\
\text { influenza virus }(\%)\end{array}$ & $\begin{array}{l}\text { Predominant } \\
\text { influenza-like virus } \\
(\%)\end{array}$ \\
\hline $\begin{array}{l}2008 / \\
2009\end{array}$ & 3379 & $56.8 / 43.2$ & A/H1N1/pdm09 (54.5) & RSV (54.6) \\
\hline $\begin{array}{l}2009 / \\
2010\end{array}$ & 6185 & $87.3 / 12.7$ & A/H1N1/pdm09 (73.2) & RSV (56.7) \\
\hline $\begin{array}{l}2010 / \\
2011\end{array}$ & 2718 & $76.3 / 23.7$ & A/H1N1/pdm09 (67.1) & RSV (74.0) \\
\hline $\begin{array}{l}2011 / \\
2012\end{array}$ & 2066 & $21.4 / 78.6$ & A/H1N1/pdm09 (24.3) & RSV (86.7) \\
\hline $\begin{array}{l}2012 / \\
2013\end{array}$ & 6949 & $75.8 / 24.2$ & A/H1N1/pdm09 (58.5) & RSV (87.0) \\
\hline $\begin{array}{l}2013 / \\
2014\end{array}$ & 2620 & $42.7 / 57.3$ & A/H3N2/ (30.6) & RSV (84.5) \\
\hline $\begin{array}{l}2014 / \\
2015 \\
\end{array}$ & 2512 & $68.7 / 31.3$ & A/H1N1/pdm09 (13.2) & RSV (91.4) \\
\hline $\begin{array}{l}2015 / \\
2016\end{array}$ & 8367 & $94.3 / 5.7$ & A/H1N1/pdm09 (49.7) & RSV (77.5) \\
\hline $\begin{array}{l}2016 / \\
2017\end{array}$ & 3977 & $94.5 / 5.5$ & A/H3N2/ (29.7) & RSV (87.5) \\
\hline $\begin{array}{l}2017 / \\
2018\end{array}$ & 5793 & $96.7 / 3.3$ & $\begin{array}{l}\text { B lineage Yamagata } \\
(65.5)\end{array}$ & RSV (63.1) \\
\hline
\end{tabular}

to $3.3 \%$ in $2017 / 2018$. It is worthy of note that RSV infection predominated in each epidemic season, with the confirmation rate ranging from $54.6 \%$ in $2008 / 2009$ to $91.4 \%$ in $2014 / 2015$ among all the other influenza-like viruses. Interestingly, influenza-like infections were more frequent than true influenza infections in the 2013/ 2014 season (Table 1).

\section{Discussion}

One of the basic goals of epidemiological and virological surveillance, which has been initiated in 1947, is to protect humanity from the threat of influenza. This goal has been reiterated in the 2019 publication of WHO entitled "Global Influenza Strategy 2019-2030" (WHO 2019). The surveillance is designed to monitor the spread of influenza virus from animals to humans. Molecular biology has been used to define the type of virus that circulates in a population in a given epidemic season as a candidate for the optimum seasonal composition of influenza vaccine.
Further, influenza and influenza-like infection morbidity, comorbidity, and death have been recorded and expressed as the incidence of confirmed and suspected cases, the number of referrals to hospital, and variable activities of circulating influenza $A$ and $B$ type and influenza-like viruses. There are over 200 respiratory influenza-related viruses that circulate in the population. Therefore, virological surveillance is essential from both confirmatory and clinical standpoints. The latter has to do with advance preparation of proper vaccine composition for each upcoming season, taking into account the genetic and antigenic diversity of recently circulating influenza viruses as well as with the use of recently available novel antiviral medicines.

In the past, Poland used to send reports to the WHO Collaborating Center for Reference and Research on Influenza of the National Institute for Medical Research in London and then as of the 2015/2016 season to the WHO Collaborating Center for Reference and Research on Influenza of the Francis Crick Institute in London. On the 
basis of reports submitted by national influenza centers, virological situation can be traced in a given continent and also worldwide. In its current form, the Global Influenza Surveillance and Response System consists of 6 WHO Collaborating Centers for Reference and Research and 149 National Influenza Centers, including 1 in the Department of Influenza Research of the National Influenza Center at the NIPH-NIH. Their main task is to send epidemiological and virological reports and full documentation on selected isolated influenza viruses to relevant WHO reference centers.

In the case of the 2008/2009 season, the peak of influenza in both Poland and Europe fell on the 1st week of February 2009 (MRC 2008). Influenza A/H1N1/pdm09 was the predominant type A virus, which was confirmed in Europe in 53\% of the submitted reports. Likewise, the confirmation rate for this virus amounted to $54.5 \%$ in Poland. There were no influenza-related deaths recorded in Poland in that season (Czarkowski et al. 2011).

In the 2009/2010 season, Europe was dominated by influenza virus $\mathrm{A}$, subtype $\mathrm{A} / \mathrm{H} 1 \mathrm{~N} 1 / \mathrm{pdm} 09$. Although many infections were caused by travelers entering a country, this virus prevailed in most countries in which it has already stayed and widely circulated. According to a WHO report, seasonal influenza viruses $\mathrm{A} / \mathrm{H} 1 \mathrm{~N} 1 /, \mathrm{A} / \mathrm{H} 3 \mathrm{~N} 2 /$, and type B continued to circulate, albeit at rather low levels. In Europe, the highest incidence and number of deaths due to infection with $\mathrm{A} / \mathrm{H} 1 \mathrm{~N} 1 / \mathrm{pdm} 09$ virus was recorded in the United Kingdom. In Poland, according to NIPH-NIH data, the number of reported cases of influenza infection was very low in the 2009/2010 season when compared with other seasons and also with data from other European countries. The peak incidence was exceptionally early in Poland as it took place in the last week of November 2010. Influenza A (H1N1)pdm09 was the predominant type A virus (MRC 2009). The 2010/2011 influenza season appeared 8-10 weeks later than that of the previous pandemic season in Europe, but still rather early compared to historical trends. In
Poland, the peak incidence was recorded in the first week of February 2011 (Woźniak-Kosek et al. 2012). Influenza A/H1N1/pdm09 remained the predominant circulating virus, but in contrast to the previous season, there were a greater co-circulation of influenza type B and an appreciable downtrend in the percentage of influenza A/H3N2/ virus (MRC 2010).

In the 2011/2012 season, influenza virus activity began late in Europe. In Poland, the peak incidence was recorded on March 16-22, i.e., in the 11th week of 2012, and it was lower than those in the preceding seasons. In Europe, influenza A virus predominated and accounted for $90.5 \%$ of all infections, whereas influenza B virus accounted for $9.5 \%$. A different level of influenza virus activity was recorded, depending on the region. In general, influenza $\mathrm{A} / \mathrm{H} 3 \mathrm{~N} 2 /$ predominated, but there was a discrepancy between the countries of Western Europe in which the virus was more than twofold more frequent than in Eastern Europe (MRC 2011). In Poland, due to a considerable percentage of unsubtyped A virus, it was hard to unambiguously confirm the predominance of $\mathrm{A} / \mathrm{H} 1 \mathrm{~N} 1 /$ pdm09. Nonetheless, the activity of influenza A viruses was confirmed in $21.4 \%$. On the other side, circulation of influenza-like viruses was confirmed in $78.6 \%$ of all infections in Poland, with the predominance of RSV that accounted for $86.7 \%$ of influenza-like illness (Table 1).

In the 2012/2013 season, peak incidence was recorded in the 3rd week of January 2013. Influenza infections were recorded throughout Europe, with the predominating type A virus which accounted for $62 \%$ of all infections and clearly predominated over type B which accounted for merely 38\% (MRC 2012). However, there were regional differences noted in the proportion of the two types as type A constituted 59\% and type B $41 \%$ of infections in Western Europe whereas these proportions were $75 \%$ and $25 \%$, respectively, in Eastern Europe. Concerning type A, subtype $\mathrm{A} / \mathrm{H} 1 \mathrm{~N} 1 / \mathrm{pdm} 09$ was recorded in $66 \%$, and subtype $\mathrm{A} / \mathrm{H} 3 \mathrm{~N} 2 /$ in $34 \%$. In Poland, influenza A/H1N1/pdm09 also predominated being responsible for $58.5 \%$ of all infections. In general, 
influenza virus activity was higher than that recorded in the previous season (Czarkowski et al. 2014).

According to a WHO report, type A virus predominated over the type B virus in Europe in the $2013 / 2014$ season: $93 \%$ and $7 \%$ of infections, respectively. Concerning influenza type A, subtype $\mathrm{A} / \mathrm{H} 1 \mathrm{~N} 1 / \mathrm{pdm} 09$ was slightly more common than A/H3N2/: $56 \%$ and 44\%, respectively. In the European Economic Area (EEA) countries, for a change, subtype $\mathrm{H} 3 \mathrm{~N} 2$ predominated over $\mathrm{A} / \mathrm{H} 1 \mathrm{~N} 1 / \mathrm{pdm} 09$ in a ratio of approximately 2.8 (MRC 2013). Overall, influenza viral activity was relatively very low and remained so even in the 8th week of 2014, when the highest number of influenza cases was detected. The predominating virus type differed among various countries. In terms of geographical spread, regional activity was largely limited to Western and Southern Europe. In some countries, detection of type A virus appreciably exceeded that of type $\mathrm{B}$ virus, and the proportion of subtype $\mathrm{A} / \mathrm{H} 1 \mathrm{~N} 1 /$ to A/H3N2/ demonstrated a substantial variability. In Poland, influenza A/H3N2/ virus was the predominant type A virus as it was recorded in $30.6 \%$ of all infections (Kondratiuk et al. 2016; Bednarska et al. 2015).

The peak incidence in the 2014/2015 season in Europe, including Poland, was recorded in the 8th week of 2015. For the entire European area, influenza type A virus predominance was confirmed in $69 \%$, and type B virus in $31 \%$ (MRC 2014). Concerning type A virus, subtype A/H3N2/ (77\%) predominated over $\mathrm{A} / \mathrm{H} 1 \mathrm{~N} 1 / \mathrm{pdm} 09$ (23\%) (Bednarska et al. 2016c). The number of confirmations of $\mathrm{A} / \mathrm{H} 3 \mathrm{~N} 2 /$ significantly exceeded that of $\mathrm{A} / \mathrm{H} 1 \mathrm{~N} 1 / \mathrm{pdm} 09$ in most countries of Southern Europe. In Poland, due to a low number of samples tested of 2512, not all of which were sub-classified, influenza A/H1N1/pdm09 was the predominant type A virus (Bednarska et al. 2016d; Hallmann-Szelińska et al. 2016).

In the 2015/2016 season, peak influenza incidence was recorded in the 6th week of 2016 in Europe, while it was in the 7th week of 2016 in Poland (Szymański et al. 2017). Influenza type A virus predominated, confirmed in $70 \%$ of all infections in the continent, among which subtype A/H1N1/pdm09 was most frequent (49.7\%). However, in Western and Southern European regions, influenza type $\mathrm{B}$ virus was sometimes more frequent (MRC 2015).

The 2016/2017 season was characterized by an early rise in infection transmission compared to previous seasons and a lack of clear pattern of influenza spread from west to east across the European area (Francis Crick Institute 2016). Influenza $\mathrm{A} / \mathrm{H} 3 \mathrm{~N} 2 /$ was the predominant type $\mathrm{A}$ virus, confirmed in $89 \%$ of cases. In Poland, type A virus also predominated (96.7\%), but subtype $\mathrm{A} / \mathrm{H} 3 \mathrm{~N} 2 /$ was confirmed in just $29.7 \%$. Due to a substantial percentage of unsubtyped material, A/H3N2/ predominance could not be conclusively confirmed (Szymański et al. 2018, 2019; Hallmann-Szelińska et al. 2018).

Influenza activity in the 2017/2018 season began in October 2017 in the European area. The season was also characterized by a relatively early rise in infection transmission that spread from west to east throughout the area (Francis Crick Institute 2017). Initially, influenza type B virus predominated during the season and most regions. The period of peak activity was somehow lengthened, comparably to the $2012 / 2013$, 2014/2015, 2015/2016, and 2016/2017 seasons. The peak incidence of infections was reported in the 1st week of February 2018, amounting to $55 \%$. In Poland, peak incidence was shifted forward to the 4th week of February 2018, but a significant rise in confirmations of influenza virus started already in the 2nd week of January 2018 and lasted till the 2nd week of March 2018. Influenza was confirmed in $96.7 \%$ of all infections, with type B/Yamagata lineage predominating in $65.5 \%$ of these infections. All European countries and regions with the ability to sub-classify influenza viral lines reported the predominance of Yamagata lineage in this season, whereas the frequency of type A subtypes varied (Francis Crick Institute 2018).

The peak incidence of influenza infections in Poland has been in January-March each season, since the pandemic influenza of $1968 / 1969$ (Brydak 2008). In the epidemiological review 
above presented, the only exception from that pattern was the 2009/2010 season when the peak appeared in November of 2009. In nine out of the ten epidemic seasons, type A virus was the predominant source of influenza infection, whereas RSV predominated in influenza-like infections. There was an increase in confirmatory laboratory findings from season to season in relation to the number of biological samples examined, from 3.2 to $42.4 \%$ over the decade. Although the number of samples examined largely increased, it has remained just a fraction of a percentage point of the cases and suspected cases of infection, reported by health-care providers, which enormously increased from 568,958 in the $2008 / 2009$ season to $5,337,997$ in the 2017/2018 season. Influenza infection remains a health scourge and a major socioeconomic burden, with a dismally low yearly vaccination rate, which recently barely reaches about $3.5 \%$ of the general population in Poland.

Acknowledgments Funded by NIPH-NIH thematic subject $1 / \mathrm{B}$.

Conflict of Interest The authors declare no conflicts of interest in relation to this article.

Ethical Approval All procedures and studies described in this review were conducted in accordance with the ethical standards of the institutional and/or national research committee and with the 1964 Helsinki declaration and its later amendments or comparable ethical standards. The article gained approval from the scientific board of the NIPH-NIH institutes in Warsaw, Poland.

Informed Consent As there was no current involvement of human studies in this review article, consent from individual participants was not required.

\section{References}

Bednarska K, Hallmann-Szelińska E, Kondratiuk K, Brydak LB (2015) Evaluation of the activity of influenza and influenza-like viruses in the epidemic season 2013/2014. Adv Exp Med Biol 857:1-7

Bednarska K, Hallmann-Szelińska E, Kondratiuk K, Brydak LB (2016a) Surveillance of influenza. Adv Hyg Exp Med 70:313-318
Bednarska K, Hallmann-Szelińska E, Kondratiuk K, Brydak LB (2016b) Innovations in the surveillance of influenza in Poland. Probl Hig Epidemiol 97:101-105

Bednarska K, Hallmann-Szelińska E, Kondratiuk K, Brydak LB (2016c) Antigenic drift of A/H3N2/ virus and circulation on influenza-like viruses during the 2014/2015 influenza season in Poland. Adv Exp Med Biol 905:33-38

Bednarska K, Hallmann-Szelińska E, Kondratiuk K, Rabczenko D (2016d) Molecular characteristics of influenza virus type B lineages circulating in Poland. Adv Exp Med Biol 910:1-8

Broberg E, Snacken R, Adlhoch C, Beauté J, Galinska M, Pereyaslov D, Brown C, Penttinen P, European Region WHO, The European Influenza Surveillance Network (2015) Start of the 2014/15 influenza season in Europe: drifted influenza $\mathrm{A}(\mathrm{H} 3 \mathrm{~N} 2)$ viruses circulate as dominant subtype. Euro Surveill 20(4):pii:21023

Brydak LB (2008) Surveillance of influenza. Influenza, pandemic flu myth or real threats? RYTM Publishing House, pp 165-190

Cieślak K, Kowalczyk D, Szymański K, Brydak LB (2017) The sentinel system as the main influenza surveillance tool. Adv Exp Med Biol 980:37-43

Cieślak K, Szymański K, Kowalczyk D, HallmannSzelińska E, Brydak LB (2018) Virological situation in Poland in the 2016/2017 epidemic season based on sentinel data. Adv Exp Med Biol 108:63-67

Czarkowski M, Romanowska M, Staszewska E, Stefańska I (2011) Influenza in Poland in 2009. Epidemiol Rev 65:199-203

Czarkowski MP, Hallmann-Szelińska E, Staszewska E, Bednarska K (2014) Influenza in Poland in 2011-2012 and 2012/2013 epidemic seasons. Epidemiol Rev 68:455-463

Francis Crick Institute (2016) Worldwide Influenza Centre WHO CC for Reference \& Research on Influenza, London. Report prepared for the WHO annual consultation on the composition of influenza vaccine for the Northern Hemisphere 2016-2017. 22nd-24th February 2016. https:/www.crick.ac.uk/sites/default/ files/2018-07/crick_feb2016_vcm_report_to_post.pdf. Accessed on 15 Nov 2019

Francis Crick Institute (2017) Worldwide Influenza Centre WHO CC for Reference \& Research on Influenza, London. Report prepared for the WHO annual consultation on the composition of influenza vaccine for the Northern Hemisphere 2017-2018. 25th-27th September 2017. https://www.crick.ac.uk/sites/ default/files/2018-07/crick_nh_vcm_report_feb_ 2017_v2.pdf. Accessed on 15 Nov 2019

Francis Crick Institute (2018) Worldwide Influenza Centre WHO CC for Reference \& Research on Influenza, London. Report prepared for the WHO annual consultation on the composition of influenza vaccine for the Northern Hemisphere 2018-2019. 19th-21st February 2018. https://www.crick.ac.uk/sites/default/files/201807/crick_feb2018_report_for_the_web.pdf. Accessed on 15 Nov 2019 
Hallmann-Szelińska E, Bednarska K, Korczyńska M, Paradowska-Stankiewicz I (2016) Virological characteristics of the 2014/2015 influenza season based on molecular analysis of biological material derived from I-MOVE study. Adv Exp Med Biol $857: 45-40$

Hallmann-Szelińska E, Cieślak K, Szymański K, Kowalczyk D, Korczyńska MR, ParadowskaStankiewicz I, Brydak LB (2018) Detection of influenza in the epidemic season 2016/2017 based on IMOVE+ project. Adv Exp Med Biol 1114:77-82

Kondratiuk K, Czarkowski M, Hallmann-Szelińska E, Staszewska E, Bednarska K, Cielebąk E, Brydak LB (2016) Influenza in Poland in 2013 and 2013/2014 epidemic season. Przegl Epidemiol 70:407-419

MRC (2008) National Institute for Medical Research. WHO Influenza Centre, London. Report March 2008. https://www.crick.ac.uk/sites/default/files/2018-07/ interim_report_mar_2008.pdf. Accessed on 15 Nov 2019

MRC (2009) National Institute for Medical Research, WHO Influenza Centre, London. Report February 2009. https://www.crick.ac.uk/sites/default/files/201807/interim_report_feb_2009.pdf. Accessed on 15 Nov 2019

MRC (2010) National Institute for Medical Research, WHO Influenza Centre, London. Report prepared for the WHO annual consultation on the composition of influenza vaccine for the Northern Hemisphere. 14th18th February 2010. https://www.crick.ac.uk/sites/ default/files/2018-07/interim_report_feb_2010.pdf. Accessed on 15 Nov 2019

MRC (2011) National Institute for Medical Research, WHO Influenza Centre, London. Report prepared for the WHO annual consultation on the composition of influenza vaccine for the Northern Hemisphere. 14th17th February 2011; https://www.crick.ac.uk/sites/ default/files/2018-07/interim-report-feb-2011.pdf. Accessed on 15 Nov 2019

MRC (2012) National Institute for Medical Research, WHO Influenza Centre, London. Report prepared for the WHO annual consultation on the composition of influenza vaccine for the Northern Hemisphere. 14th17th February 2011. https://www.crick.ac.uk/sites/ default/files/2018-07/interim-report-feb-2012.pdf; https://www.who.int/influenza/vaccines/virus/ recommendations/consultation201209/en/. Accessed on 15 Nov 2019

MRC (2013) National Institute for Medical Research, WHO Influenza Centre, London. Report prepared for the WHO annual consultation on the composition of influenza vaccine for the Northern Hemisphere 2013/ 14. 18th-20th February 2013. https://www.crick.ac.uk/ sites/default/files/2018-07/interim_report_february_ 2013.pdf. Accessed on 15 Nov 2019

MRC (2014) National Institute for Medical Research, WHO Influenza Centre, London. Report prepared for the WHO annual consultation on the composition of influenza vaccine for the Northern Hemisphere 2014/ 15. 17th-19th February 2014. https://www.crick.ac.uk/ sites/default/files/2018-07/nimr-report-feb2014-web. pdf. Accessed on 15 Nov 2019

MRC (2015) National Institute for Medical Research. WHO Influenza Centre, London. Report prepared for the WHO annual consultation on the composition of influenza vaccine for the Northern Hemisphere 2015/ 16. 23rd-25th February 2015. https://www.crick.ac. uk/sites/default/files/2018-07/nimr-report-feb2015web.pdf. Accessed on 15 Nov 2019

Szymański K, Kowalczyk D, Cieślak K, Brydak LB (2017) Regional diversification of influenza activity in different in Poland during the epidemic 2015/2016 epidemic season. Adv Exp Med Biol 1020:1-8

Szymański K, Kowalczyk D, Cieślak K, HallmannSzelińska E, Brydak LB $(2018,1108)$ Infections with influenza A/H3N2/ subtype in Poland in the 2016/2017 epidemic season. Adv Exp Med Biol:93-98

Szymański K, Cieślak K, Kowalczyk D, HallmannSzelińska E, Brydak LB (2019) Respiratory viruses in different provinces of Poland during the epidemic season 2016/2017. Adv Exp Med Biol:1150, 83-1188

WHO (2019) The Global Influenza Strategy 2019-2030. https://www.who.int/influenza/global_influenza_strat egy_2019_2030/en/. Accessed on 14 Nov 2019

Woźniak-Kosek A, Czarkowski MP, Staszewski E, Kondej B (2012) Influenza in Poland in 2010. Epidemiol Rev 66:599-604 